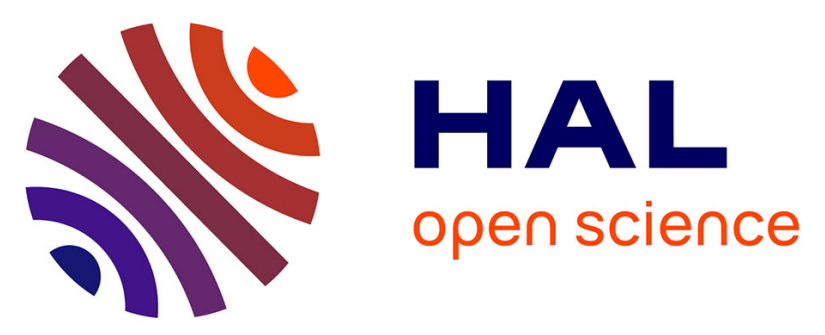

\title{
Aqueous suspensions of Fuller's earth potentiate the adsorption capacities of Paraoxon and improve skin decontamination properties
}

Alix Danoy, Kardelen Durmaz, Margaux Paoletti, Laetitia Vachez, Annick Roul, Jérôme Sohier, Bernard Verrier

\section{To cite this version:}

Alix Danoy, Kardelen Durmaz, Margaux Paoletti, Laetitia Vachez, Annick Roul, et al.. Aqueous suspensions of Fuller's earth potentiate the adsorption capacities of Paraoxon and improve skin decontamination properties. Journal of Hazardous Materials, 2022, pp.127714. 10.1016/j.jhazmat.2021.127714 . hal-03439293

\section{HAL Id: hal-03439293 \\ https://hal.science/hal-03439293}

Submitted on 22 Nov 2021

HAL is a multi-disciplinary open access archive for the deposit and dissemination of scientific research documents, whether they are published or not. The documents may come from teaching and research institutions in France or abroad, or from public or private research centers.
L'archive ouverte pluridisciplinaire HAL, est destinée au dépôt et à la diffusion de documents scientifiques de niveau recherche, publiés ou non, émanant des établissements d'enseignement et de recherche français ou étrangers, des laboratoires publics ou privés. 


\section{Journal Pre-proof}

Aqueous suspensions of Fuller's earth potentiate the adsorption capacities of Paraoxon and improve skin decontamination properties

Alix Danoy, Kardelen Durmaz, Margaux Paoletti, Laetitia Vachez, Annick Roul, Jérôme Sohier, Bernard Verrier

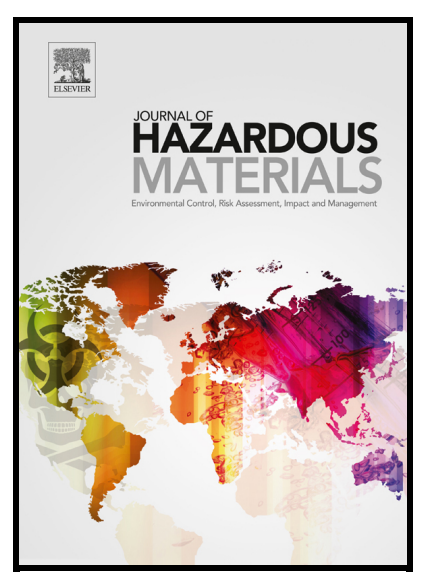

PII: $\quad$ S0304-3894(21)02682-0

DOI: $\quad$ https://doi.org/10.1016/j.jhazmat.2021.127714

Reference: HAZMAT127714

To appear in: Journal of Hazardous Materials

Received date: 16 August 2020

Revised date: 2 November 2021

Accepted date: 3 November 2021

Please cite this article as: Alix Danoy, Kardelen Durmaz, Margaux Paoletti, Laetitia Vachez, Annick Roul, Jérôme Sohier and Bernard Verrier, Aqueous suspensions of Fuller's earth potentiate the adsorption capacities of Paraoxon and improve skin decontamination properties, Journal of Hazardous Materials, (2020) doi:https://doi.org/10.1016/j.jhazmat.2021.127714

This is a PDF file of an article that has undergone enhancements after acceptance, such as the addition of a cover page and metadata, and formatting for readability, but it is not yet the definitive version of record. This version will undergo additional copyediting, typesetting and review before it is published in its final form, but we are providing this version to give early visibility of the article. Please note that, during the production process, errors may be discovered which could affect the content, and all legal disclaimers that apply to the journal pertain.

(C) 2020 Published by Elsevier. 


\title{
Aqueous suspensions of Fuller's earth potentiate the adsorption capacities of Paraoxon and improve skin decontamination properties
}

\author{
Alix Danoy ${ }^{1}$, Kardelen Durmaz ${ }^{1,{ }^{*}}$, Margaux Paoletti ${ }^{1}$, Laetitia Vachez ${ }^{1}$, Annick Roul ${ }^{1,2}$, Jérôme Sohier ${ }^{1}$ \& \\ Bernard Verrier ${ }^{1}$ \\ ${ }^{1}$ UMR 5305: Laboratoire de Biologie Tissulaire et d'Ingénierie Thérapeutique, CNRS / Université Claude Bernard Lyon 1, \\ Institut de Biologie et Chimie des Protéines, 7 passage du Vercors, 69367 Lyon cedex 07, France. \\ ${ }^{2}$ Pôle Santé, Direction Générale de la Sécurité Civile et de la Gestion des Crises, Ministère de l'Intérieur Paris, France \\ *Correspondence : kardelen.durmaz@ibcp.fr
}

\begin{abstract}
Fuller's earth (FE) is a phyllosilicate used as a powder for household or skin decontamination due to its adsorbent properties. Recent studies have shown that water suspensions exhibit similar adsorbent capacities. FE is heterogeneous due to its composition of elementary clay aggregates and heavy metal particles. Here, FE toxicity was assessed in vitro on skin cells and in vivo on Danio rerio embryos. Among the suspensions tested $(5 \%, 9.1 \%$ and $15 \% \mathrm{w} / \mathrm{w})$, only the highest one shows weak toxicity. Suspensions were tested for ex vivo dermal decontamination into pig ear skin and human abdominal skin using diffusion cells and paraoxon as organophosphorus contaminant. After 24 hours of diffusion, no difference was observed in the paraoxon concentration in the receptor compartment whether the decontamination was carried out with $\mathrm{FE}$ in powder or in suspension form. In presence of FE suspensions, we observed the disappearance of paraoxon from the stratum corneum, the reservoir compartment, independently of the suspensions' concentration. We suggest that water potentiates the absorbing capacities of FE powder by intercalating between clay lamellas leading to the appearance of new adsorption zones and swelling. These data support the use of FE aqueous suspensions as a safe tool for organophosphorus skin decontamination.
\end{abstract}

Keywords: smectite; paraoxon; toxicity; skin penetration; decontamination efficiency

\section{Graphical abstract :}

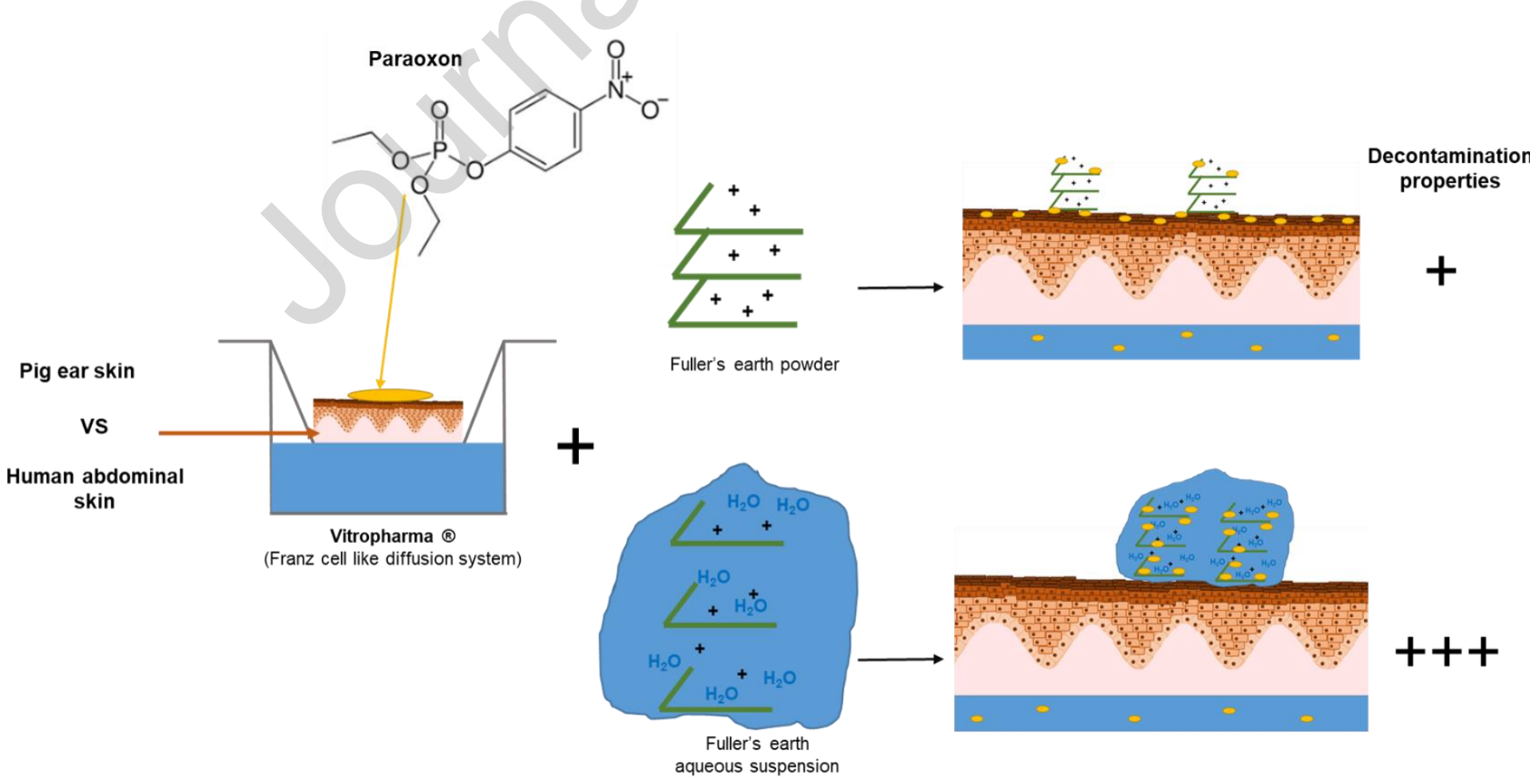




\section{Introduction}

Fuller's earth (FE) is a clay that has been used for hundreds of years for woolen fulling in order to clean wool to eliminate oils, dirt and impurities (Kherdekar \& Adivarekar, 2017). Due to its adsorptive capacities, modern uses of FE have been extensively developed, ranging from absorbent for cat litter to carrier for fertilizers or active ingredient in cosmetic products (Rehan et al., 2019). Interestingly, one of its most intriguing use concerns dry skin decontamination in the military field. Indeed, chemical warfare agent (CWA) still represents a threat, both for civilian (Ciottone, 2018; Haines \& Fox, 2014; Pitschmann, 2014) and military populations. Organophosphorus compounds (OPC) are among the most detected chemical compounds in the environment due to their use as pesticides (such as paraoxon (POX)) and nerve agents (tabun, sarin, soman, VX) (Naughton \& Terry, 2018). Because most OPCs have a low volatility, their absorption through the dermal route remains predominant in comparison with the respiratory one (John et al., 2015; Thors et al., 2016), meaning that any system acting by adsorption and displacement of the toxic agent from the skin surface could be an efficient decontaminant product. Thus, $\mathrm{FE}$, which is unexpansive, easy to obtain, and composed of layers with high ion exchange capacities (Taylor et al., 2006) favoring interaction with OPCs, has largely been used for OPCs decontamination. As illustrated by previous ex vivo and in vivo studies, this phyllosilicate has been shown to be the reference agent applied for skin decontamination following CWA exposure (Bjarnason et al., 2008; Chilcott et al., 2001; Taysse et al., 2011).

$\mathrm{FE}$ is a dusty agent that easily induces aerosols, favoring the propagation of contaminated dust and particles which could be inhaled by surrounding people and thus represents a new threat by cross-contamination (Denet et al., 2020). One way to bypass this problem could be the use of water suspension of FE as recently described (Roul et al., 2017). Even if most of the OPC materials have low water-solubility (for example POX is soluble at $2.4 \mathrm{~g} / \mathrm{L}$ ), an aqueous suspension of FE could offer a strong added value for decontamination. In their paper, Roul and collaborators (Roul et al., 2017) have shown that aqueous suspension of FE (10g into $100 \mathrm{~mL}$ ) limit skin penetration of 4-cyanophenol. Thus, suspension's decontamination efficacy of this compound was proved to be better than FE powder or water alones, meaning that the contaminant is better entrapped.

In order to further investigate these observations, we decided to analyze the decontaminant properties of different concentration of FE suspension to highlight a potential dose effect decontamination efficacy. As skin is the first barrier to protect the body from external assaults, especially with OPC, we have explored the penetration of an OPC through this semi-permeable barrier to analyze if $\mathrm{FE}$ suspensions could diminish it. Ex vivo diffusion assays were done with specific derived Franz-cells (Salmon et al., 2015) (see figure S1 in supplementary data) allowing multiple runs at the same time and ensuring strong reproducibility. These devices consist of a donor and receiver compartments separated by a membrane make it possible to mimic passive cutaneous diffusion (Misik et al., 2011). Pig skin is commonly used as predictive model for human skin permeability because of the histological and pathophysiological similarities between the two species (Godin \& Touitou, 2007; Matar et al., 2014). Although expensive and difficult to obtain, human skin remains the best model for ex vivo penetration study seeing as no interspecies extrapolation is needed (Moore et al., 2014) (Hui et al., 2012).

The primary aim of this study was to investigate the toxicity of different FE aqueous suspensions. This analysis is essential because the water in the suspension could favor the release of toxic compounds, such as heavy metals entrapped into Fuller's earth aggregates, jeopardizing the use of such decontamination system. The evaluation has been done in vitro on skin cells and in vivo on Danio rerio embryos. After toxicological validation of the suspensions, their effectiveness as a decontamination tool has been evaluated ex vivo with skin diffusion assays. POX was used as simulant agent for VX (Bartelt-Hunt et al., 2008; Sellik et al., 2017) and chose for its lower toxicity and its intrinsic properties (see table $\mathbf{S 1}$ in supplementary data). Furthermore, both pig ear and human abdominal skins have been used as model in order to determine if pig ear skin can be considered as a good predictive model of human skin for this contaminant.

\section{Materials and Methods}

\subsection{Material}


Fuller's earth (FE) was purchased as a free powder with adsorptive properties available for fire-fighter decontamination process (NBC-Sys, France).

\subsection{Toxicity}

\subsubsection{In vitro cell toxicity}

Normal Human Dermal Fibroblasts (NHDF), passages 9 to 12, were cultured in Dulbecco's Modified Eagle's Medium (DMEM) supplemented with 10\% Fetal Bovine Serum, 1\% Penicillin-Streptomycin (5000 U/mL). Human primary keratinocytes (HPK) extracted from foreskin, passage 1 to 4 , were cultured in keratinocytes-SFM medium supplemented with bovine pituitary extract, $1 \%$ Penicillin-Streptomycin $(5000 \mathrm{U} / \mathrm{mL})$, Epidermal Growth Factor and $\mathrm{Cacl}_{2}$. Both cell lineages were maintained in a $37{ }^{\circ} \mathrm{C}$ incubator (Heracell 150i, Thermo Scientific USA), under $5 \% \mathrm{CO}_{2}$ and $95 \%$ humidity. All the compounds for the cell media were purchased from Gibco (Thermo Fisher Scientific, USA). Three FE suspensions were prepared, respectively 5\%, 9.1\% and $15 \%$ $\mathrm{w} / \mathrm{w}$, in PBS $1 \mathrm{X}$ (Gibco, USA) and then filtered on $0.22 \mu \mathrm{m}$ single-use polycarbonate filters (Merck Millipore, USA). The filtered supernatants were left at room temperature until they were added into cells for 30 minutes of incubation before washing with cell media and cell viability evaluation by the MTT technique. Cytotoxicity assays were done 40 hours after the coating of 96 wells plate with a density of 10000 or 15000 cells per well for respectively NHDF and HPK, with MTT cytotoxicity assays reagent from Sigma Aldrich (USA) as described by the protocol.

The values for the culture media and tested ones (i.e. PBS 1X, SD 5\% and the three supernatants from the three FE suspensions) were compared and statistically analyzed using a two-way ANOVA coupled with Dunnett multiple comparison post hoc analysis.

\subsubsection{In vivo Danio rerio toxicity}

Fish embryo toxicity test (FET) on zebrafish (Danio rerio) was made in agreement with OECD 236 guideline (see figure S2 in supplementary data). Briefly, zebrafish were obtained from Institut de Génomique Fonctionnelle de Lyon (IGFL) where they were maintained in closed flow-through system with a temperature of $26^{\circ} \mathrm{C} \pm 1{ }^{\circ} \mathrm{C}$ and a $16 \mathrm{~h}$ light / $8 \mathrm{~h}$ dark cycle. After fertilization, newly fertilized eggs were collected and selected under binocular microscope: embryos with normal development staging from the zygote stage to the gastrula stage were distributed on a 24-well plate (Thermo Fisher Scientific, USA), one embryo per well. One condition per plate was tested: 3,4-dichloroaniline (Sigma Aldrich, France) at $8 \mu \mathrm{g} / \mathrm{mL}$ used as negative control, aquarium water (E3) used as positive control, and FE suspensions in water aquarium at $5 \%, 9.1 \%$ and $15 \% \mathrm{w} / \mathrm{w}$. Every well was filled with $2 \mathrm{~mL}$ of solution, and embryos viability was assessed every $24 \mathrm{~h}$ using microscope and toxicological endpoints as criterions (coagulated embryo, absence of heartbeat, non-detachment of the tail, absence of somitis formation) for 4 days. Alive fishes were analyzed to determine if they had any morphological abnormalities before observing their mobility with a Zebrabox equipped with Zebralab software (Viewpoint Behavior Technology, France) by 5 minutes' light cycle exposition before 3 minutes' dark cycle.

The values for the aquarium media (E3) and tested ones (i.e. 3.4-dichloroaniline and the three FE aqueous suspensions) were compared and statistically analyzed using a two-way ANOVA coupled with Dunnett multiple comparison post hoc analysis.

\subsection{Ex vivo cell diffusion assays}

VitroPharma ${ }^{\circledR}$ (patent $\mathrm{n}^{\circ}$ WO2013057401) was used as cell diffusion system (see figure S1 in supplementary data). Dermatomed skin at $500 \mu \mathrm{m}$, either from pig ear or human abdomen, with a diffusion-available area of $0.71 \mathrm{~cm}^{2}$ was mounted in the system with the dermis facing the receptor compartment filled with $5 \mathrm{~mL}$ of PBS $1 \mathrm{X}$ as receptor media. Heated magnetic stirrer was used to heat receptor fluid to $37^{\circ} \mathrm{C} \pm 1{ }^{\circ} \mathrm{C}$, which allowed the skin to be at $32^{\circ} \mathrm{C}$ (i.e. the physiological average temperature of human skin surface), and to homogenize it with a magnetic rod according to the OECD 428 guideline.

\subsubsection{Skin explants}

Frozen pig ears (Proviskin, France) obtained from a slaughterhouse were thawed, shaved and dermatomed (Aesculap GA 630 model) at $500 \mu \mathrm{m}$. Individual disks of $2 \mathrm{~cm}^{2}$ were cut off to fit into VitroPharma system. 
Abdominal human skin (Proviskin, France) was obtained after approval from women who have had abdominal plastic surgery and stored as frozen $2 \mathrm{~cm}^{2}$ disks dermatomed at $500 \mu \mathrm{m}$. Before the experiment, each skin explant was controlled with a caliper in order to have a homogeneous thickness of $500 \mu \mathrm{m} \pm 50 \mu \mathrm{m}$, and skin integrity was visually assessed by microscopy.

\subsubsection{Decontamination protocols}

Contaminated skins were obtained after the deposit of $10 \mu \mathrm{L} / \mathrm{cm}^{2}$ of Paraoxon-diethyl (Sigma Aldrich, France) (paraoxon or POX) as simulant of VX nerve agent. In accordance with the standard NF X52-122, decontamination was realized after 30 minutes to evaluate decontamination efficiency for delayed decontamination. For dry decontamination, $0.16 \mathrm{~g} / \mathrm{cm}^{2}$ of Fuller's earth (NBC-Sys, France) were applied. Wet decontamination occurs through the use of water (Otec ${ }^{\circledR}$, Aguettant, France) or FE aqueous suspensions prepared at $5 \%, 9.1 \%$ and $15 \% \mathrm{w} / \mathrm{w}$ using Otec $^{\circledR}$ water (Aguettant, France). In each case $102 \mu \mathrm{l} / \mathrm{cm}^{2}$ of liquid were deposited. For both decontamination protocols, the decontaminant was left on the skin for 2 minutes before being removed and then the skin was dry by patting with a pad.

\subsubsection{Collection and treatment of samples}

To determine POX penetration kinetics, $500 \mu \mathrm{L}$ of fluid receptor were collected over time $(1,2,4,6,8,10$ and 24 hours of diffusion) and replaced by $500 \mu \mathrm{L}$ of fresh media. After the set exposure period of 24 hours, VitroPharma ${ }^{\circledR}$ diffusion cells were dismantled and the surface of skin sample was wiped with an absorbent paper in order to recover the fraction of POX remaining on the skin. Skin layers were separated using the cyanoacrylate glue method (Salerno et al., 2017) for stratum corneum (SC), and immersion into PBS 1X heated at $60{ }^{\circ} \mathrm{C}$ for epidermis and dermis. For each sample, POX was extracted for 24 hours into HPLC grade ethanol before HPLC-UV quantification.

\subsubsection{Quantification by HPLC-UV}

Concentration of POX was determined by liquid chromatography using a quaternary pump (Agilent Technologies 1260 Infinity), vial auto sampler (Agilent Technologies 1260 Infinity II) and photodiode array detector (Agilent Technologies 1200 Series). Mobile phase was composed by $52.25 \%$ of methanol (HPLC grade, Carlo Erba, Italy); $42.75 \%$ of milliQ water (ultrapure analytical water with $r=18 \mathrm{~m} \Omega / \mathrm{cm}$, Millipore, USA) and $5 \%$ of acetic acid glacial (HPLC grade, Carlo Erba, Italy), the whole at a flow rate of $0.7 \mathrm{~mL} / \mathrm{min}$. $10 \mu \mathrm{L}$ of sample were brought to the $\mathrm{C} 18$ Clipeus column $(5 \mu \mathrm{m}, 100 \times 40 \mathrm{~mm})$ heated at $40^{\circ} \mathrm{C}$. POX was identified at $269 \mathrm{~nm}$ UV wavelength with a retention time of 5.9 minutes (Salerno et al., 2017). The linearity of the method was assessed for POX concentration in the range $1.95-2000 \mathrm{ng} / \mathrm{mL}\left(R^{2}=0.999\right)$ with a limit of detection $(L O D)=0.31$ $\mathrm{ng} / \mathrm{mL}$ and a limit of quantification $(\mathrm{LOQ})=1.95 \mathrm{ng} / \mathrm{mL}$.

The value for the kinetic profiles and for the quantification into cell diffusion compartments and skin layers were compared between them and statistically analyzed using a one-way ANOVA coupled either with Dunnett or Tuckey multiple comparison post hoc analysis.

\subsection{Ex vivo evaluation of a skin decontaminant}

Skin decontamination methods need to be evaluated and compared to each other in order to determine the most effective one, based on skin penetration data. Ex vivo decontamination efficiency have been calculated as follows to compare skin decontamination methods:

$$
\mathrm{DE}(\%)=\frac{(\mathrm{Q} 3 \mathrm{~T}+\mathrm{Q} 4 \mathrm{~T})-(\mathrm{Q} 3+\mathrm{Q} 4)}{\mathrm{Q} 3 \mathrm{~T}+\mathrm{Q} 4 \mathrm{~T}} \times 100
$$

Where Q3 = the amount of POX present into skin layers (SC + epidermis + dermis) at the end of the experiment; Q4 = the amount of POX in the receptor (meaning that it passed through skin) at the end of the experiment; $T$ is for control samples 
According to the standard NF X52-122, skin decontamination has an impact on functional prognosis because of its ability to capture the contaminant on the skin's surface. The improvement of the functional prognosis for each decontamination method have been calculated as follows:

$$
\mathrm{FP}=\frac{\mathrm{Q} 2 \mathrm{~T}+\mathrm{Q} 3 \mathrm{~T}+\mathrm{Q} 4 \mathrm{~T}}{\mathrm{Q} 2+\mathrm{Q} 3+\mathrm{Q} 4}
$$

Where Q2 = the amount of POX present on the skin after decontamination; Q3 = the amount of POX present into skin layers (SC + epidermis + dermis) at the end of the experiment; $\mathrm{Q} 4$ = the amount of POX in the receptor (meaning that it passed through skin) at the end of the experiment; $\mathrm{T}$ is for control samples

\subsection{Statistical}

analysis

Data was statistically analyzed using GraphPad Prism Version 7.0 software (San Diego, CA, USA). All of the data are presented as the mean $\pm S D$, where $n=4$ for in vitro cell toxicity experiments, $n=3$ for in vivo Danio rerio toxicity experiments and $n=6$ for ex vivo skin decontamination assays. The statistical difference between groups was analyzed using either unpaired t-test, one-way ANOVA or two-way ANOVA tests followed by specific multiple comparison post-hoc tests as mentioned with each observed parameter individually.

\section{Results}

\subsection{Toxicity of Fuller's earth suspensions}

Fuller's earth is a heterogeneous smectite composed of particles sizing from nanometers to millimeters, corresponding to heavy metals particles and elementary clay aggregates. In order to assess its toxicity, it is necessary to take into account the presence of these different populations and to identify appropriate toxicity tests. First, in vitro experiments were performed using 0.22 um filtered FE suspensions, on two different skin cells to identify ultra-filterable toxicity, such as heavy metal or nanoparticles. In parallel, toxicity of the whole suspensions was assessed in vivo on zebra fish embryos model to determine the potential side effects of clay aggregates.

\subsubsection{FE suspensions' supernatant cytotoxicity}

Toxicity of particles with a size $<0.22 \mu \mathrm{m}$ was evaluated in vitro on two types of skin cells: Human Primary Keratinocytes (HPK) and Normal Human Dermal Fibroblasts (NHDF) after 30 minutes of contact (see materials and methods section 2.2.1.). As keratinocytes compose the top skin layer, which is epidermis, they are the first ones in contact with the product. Regardless of the concentration of the suspensions, no toxic effect on cell viability of FE supernatant was observed, in comparison with the two negative controls: cell media and PBS $1 \mathrm{X}$ (Figure1). NHDF, on the other hand, are founded in the dermis under the epidermis: they are in contact with an external element only in the case of a skin lesion. Interestingly, PBS $1 \mathrm{x}$ in which the suspensions were made also exhibits a significant toxic effect on NHDF, which indicates that the suspensions are not more toxic than PBS (Figure 1).

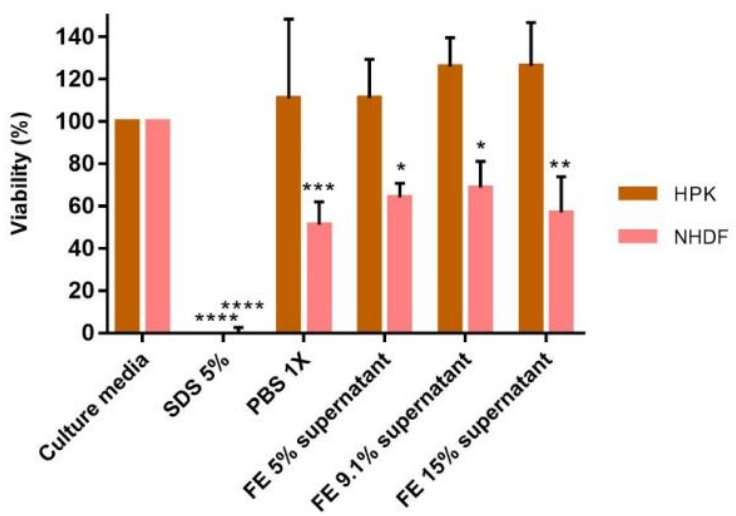

Figure 1. In vitro cell toxicity of FE supernatants filtered (size $<0.22 \mu \mathrm{m}$ ) from FE PBS $1 \mathrm{X}$ suspensions at different concentrations, on Human Primary Keratinocytes (HPK) and Normal Human Dermal Fibroblasts (NHDF) ( $n=4$ for each). Results were statistically analyzed using two- 
way ANOVA followed by Dunnett's multiple comparison tests using culture media as control treatment. Values are presented as mean \pm SD. *: $p<0.05, * *: p<0.01, * * *: p<0.005 ; * * * *: p<0.0001$

\subsubsection{In vivo toxicity of FE suspensions}

To address a potential toxicity due to the FE suspension concentration, Danio rerio fish embryos have been immerged for 4 days into different amount of FE suspensions, respectively 5, 9.1 and $15 \% \mathrm{w} / \mathrm{w}$. Their viability was assessed as described in section 2.2.2 using optical microscopy. Observations have been done to differentiate embryos without and with morphological abnormalities such as development default, curved tail or cardiac edema (Figure 2). The presented figure is a picture of the viability after 4 days of immersion, meaning that fish embryos that have died on previous days are also counted.

No significant difference was observed on global survival and the occurrence of anomalies depending on the suspensions' concentration (Figure 3). When analyzing the mean ground covered for 3 minutes of light after 4 days of immersion, the $15 \%$ suspension impact fish mobility but not significantly. However, as $15 \%$ of FE implies a strong increase in water viscosity, we could not exclude that these observations are due to physical impairment of fish mobility.

a)

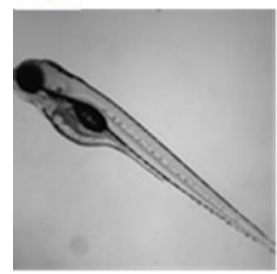

b)

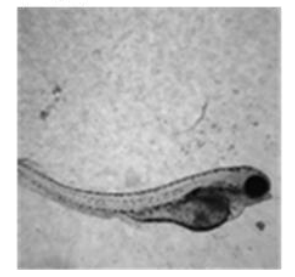

c)

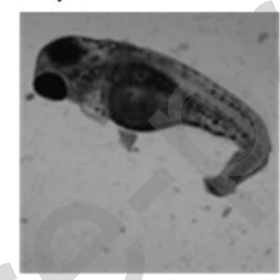

d)

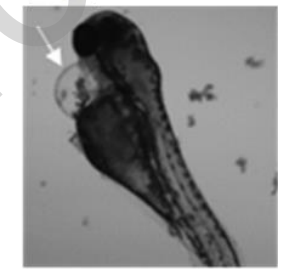

Figure 2: Morphological observation of 4 days old Danio rerio. a) Normal development; b) Global development default; c) Curved tail; d) Cardiac edema.

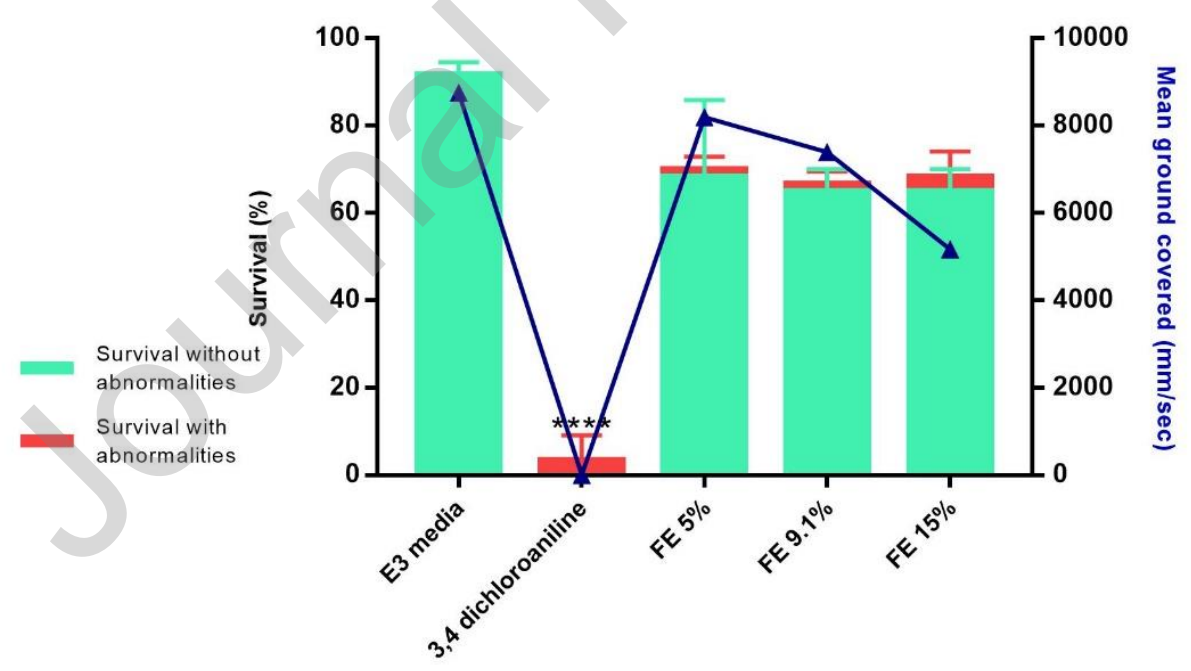

Figure 3: Survival rate of Danio rerio with and without morphological abnormalities and mean ground covered after 4 days on immersion in aquarium media (E3), negative control (3.4-dichloroaniline) and three different concentrations of FE aqueous suspensions into E3 media ( $n=3$ for each). Results were statistically analyzed using two-way ANOVA followed by Dunnett's multiple comparison tests using E3 medium as control treatment. Values are presented as mean \pm SD. ${ }^{* * * *}: \mathrm{p}<0.0001$

\subsection{Ex vivo decontamination assays}

Most of the ex vivo skin diffusion experiments are done on pig skin (Godin \& Touitou, 2007), which is also true for skin decontamination studies (Matar et al., 2014; Taysse et al., 2007). This model is widely used as human skin penetration model due to the respect of the physiopathology in relation to human skin (In et al., 2019). Nevertheless, it is still necessary to compare penetration profile for a given molecule on both skin origins as 
they differ slightly, leading to misleading extrapolations on human decontamination efficiency (Jung \& Maibach, 2015; Netzlaff et al., 2005).

\subsubsection{Differences in paraoxon penetration kinetics through pig ear skin and human abdominal skin}

Ex vivo POX penetration kinetics through pig ear skin is linear over time for 24 hours, reaching the value of $13.59 \pm 0.78 \%$ of the applied dose find in the receptor compartment (Figure 4 ). At the opposite, ex vivo skin diffusion on human abdominal skin follows a more complex kinetics. Indeed, the penetration seems to take place in several stages: it follows the same pattern as the one for pig ear skin during 4 hours before a strong increase in the amount of POX in the receptor. From 8 hours of POX diffusion, significant differences are observed between pig ear skin and human abdominal skin profiles. These observations are supported by the quantification of POX into each compartment that makes up the diffusion cell, i.e. the skin surface, the skin and the receptor, and each skin layers, i.e. stratum corneum (SC), epidermis and dermis (Table 1). Stronger significant differences between both skin origins are found in the receptor and in the skin surface, whereas pig ear epidermis contains significantly lower quantity of contaminant than the human abdominal epidermis.

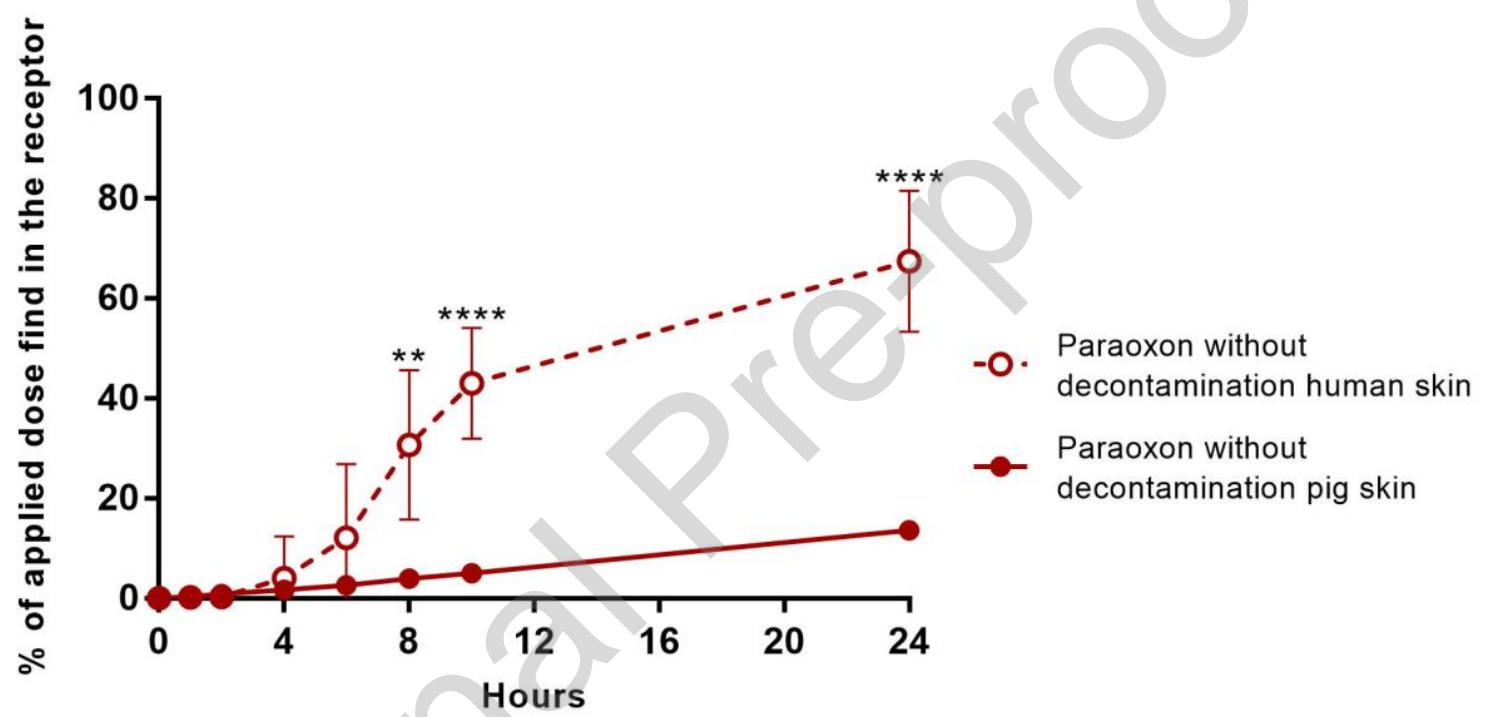

Figure 4: Ex vivo POX penetration assessment through pig ear skin and human abdominal skin without decontamination: kinetic of diffusion of applied POX dose through skin for 24 hours ( $n=6$ for each time). Results were statistically analyzed using unpaired t-test. Values are presented as mean \pm SD. ${ }^{* *}: p<0.01, * * * *: p<0.0001$

Table 1: Percentage of applied dose of POX found at the skin surface, trapped into skin layers and passed through the skin after 24 hours of diffusion without decontamination method into pig ear skin and human abdominal skin ( $n=6$ for each). Results were statistically analyzed using unpaired t-test. Values are presented as mean. ${ }^{* * *}: \mathrm{p}<0.0001$

\begin{tabular}{l|ccccc}
\hline Skin model & Skin surface & Stratum corneum & Epidermis & Dermis & Receptor \\
\hline Pig ear skin & $69.84 \%$ & $5.55 \%$ & $0.64 \%$ & $2.21 \%$ & $13.59 \%$ \\
Human abdominal skin & $3.82 \%$ & $3.13 \%$ & $1.57 \%$ & $3.99 \%$ & $67.46 \%$ \\
\hline
\end{tabular}

\subsubsection{Efficacy of FE suspension compared to FE powder and water}

After assessing the POX penetration profiles on both skin origins explants, decontamination efficiencies of FE powder, water and FE 9.1\% suspension were evaluated into both pig and human skins. This suspension' concentration was chosen as it was the one developed by Roul et al., 2017, that has proven to have a better decontamination efficiency than FE powder or water alones for 4-cyanophenol skin decontamination.

The same decontamination protocol was applied for each decontamination method and the kinetics of POX penetration through skin were evaluated for 24 hours (Figure 5). The profiles of the contaminant penetration curves differ according to the type of decontaminant used but not according to the nature of the skin. After 8 
to 10 hours of diffusion, a plateau is observable when the decontamination was done with the $9.1 \%$ suspension, whereas for FE powder and water decontamination there is only an inflection point in the curve. Despite these observations, there is not significant difference in the quantity of POX found in the receptor after 24 hours of diffusion, depending on the decontamination methods or skin origins.

At the end of the experiment, POX quantification in each skin layers highlighted differences between decontaminants and skin origins (Table 2). Indeed, after FE powder decontamination POX significantly accumulates in the SC regardless of the skin' nature. Furthermore, for this condition, when contaminant content in human abdominal skin is compared with the one in pig ear skin a significant difference showing an accumulation in favor of the first one is observed for skin surface, epidermis and dermis. Tested decontamination formulations are effective on both pig ear and human abdominal skins, with an increase efficiency between FE powder, water and FE 9.1\% suspension.

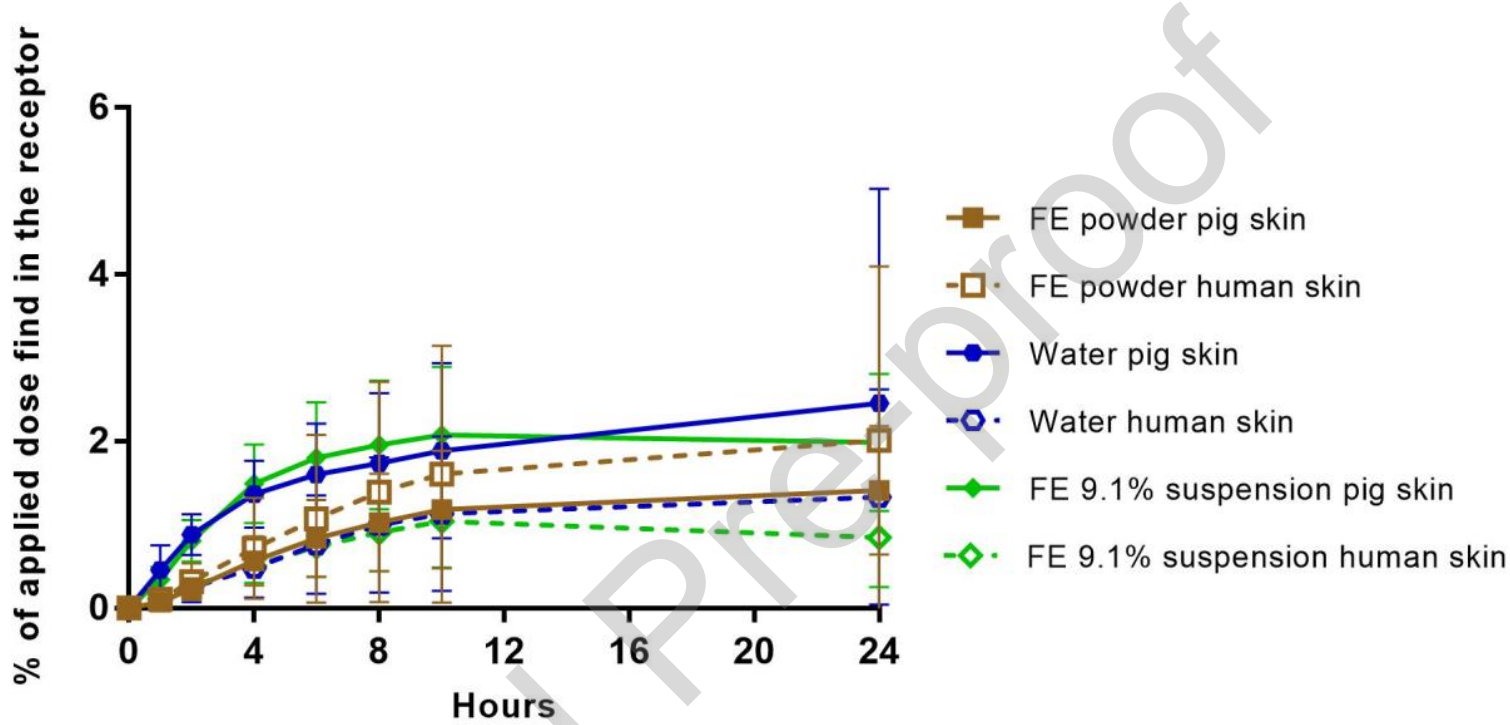

Figure 5: Ex vivo POX penetration assessment through pig ear skin and human abdominal skin with 3 decontamination methods following the same protocol (FE powder, water and FE 9.1\% aqueous suspension): kinetic of diffusion of applied POX dose through skin for 24 hours ( $n=6$ for each time). Results were statistically analyzed using two-way ANOVA followed by Tukey's multiple comparison tests. Values are presented as mean \pm SD.

Table 2: Percentage of applied dose of POX found at the skin surface, trapped into skin layers and passed through the skin after 24 hours of diffusion with 3 different decontamination methods (FE powder, water, FE 9.1\% suspension) into pig ear skin and human abdominal skin ( $n=6$ for each). Results were statistically analyzed using one-way ANOVA followed by Tukey's multiple comparison tests between each skin origins and decontamination methods. Values are presented as mean. ${ }^{*}: p<0.05,{ }^{* *}: p<0.01, * * * *: p<0.0001$

\begin{tabular}{|c|c|c|c|c|c|c|}
\hline $\begin{array}{l}\text { Decontamination } \\
\text { method }\end{array}$ & Skin model & Skin surface & $\begin{array}{l}\text { Stratum } \\
\text { corneum }\end{array}$ & Epidermis & Dermis & Receptor \\
\hline FE powder & $\begin{array}{c}\text { Pig ear skin } \\
\text { Human abdominal skin }\end{array}$ & $\begin{array}{l}0.89 \% \\
5.28 \%\end{array}$ & $\begin{array}{l}3.18 \%^{*} \\
3.98 \%^{* *}\end{array}$ & $\begin{array}{l}0.30 \% \\
1.71 \%\end{array}$ & $\begin{array}{l}0.36 \% \\
3.48 \%\end{array}$ & $\begin{array}{l}1.43 \% \\
2.01 \%\end{array}$ \\
\hline Water & $\begin{array}{c}\text { Pig ear skin } \\
\text { Human abdominal skin }\end{array}$ & $\begin{array}{l}0.78 \% \\
0.56 \%\end{array}$ & $\begin{array}{l}0.21 \% \\
0.59 \%\end{array}$ & $\begin{array}{l}0.05 \% \\
0.24 \%\end{array}$ & $\begin{array}{l}0.09 \% \\
0.46 \%\end{array}$ & $\begin{array}{l}2.45 \% \\
1.33 \%\end{array}$ \\
\hline $\begin{array}{l}\text { FE } 9.1 \% \\
\text { suspension }\end{array}$ & $\begin{array}{c}\text { Pig ear skin } \\
\text { Human abdominal skin }\end{array}$ & $\begin{array}{l}0.06 \% \\
0.48 \%\end{array}$ & $\begin{array}{c}0 \% \\
0.87 \%\end{array}$ & $\begin{array}{l}0.01 \% \\
0.29 \%\end{array}$ & $\begin{array}{l}0.02 \% \\
0.29 \%\end{array}$ & $\begin{array}{l}1.99 \% \\
0.85 \%\end{array}$ \\
\hline
\end{tabular}

\subsubsection{Relationship between FE suspensions' concentration and decontamination efficiency}

The added value of the FE 9.1\% suspension compared to FE powder in terms of POX accumulation in the SC has been illustrated by the table 2 . Then, a dose effect of FE concentration has been further investigated using $5 \%$ and $15 \%$ suspensions.

For each concentration, a plateau effect in the kinetic profile is observed from 8 hours of POX diffusion onwards, as presented in Figure 6. No significant differences are observed in the amount of contaminant in the receptor depending on the FE concentration for each suspension and on the skin origin. The contaminant 
quantification in skin layers after 24 hours of diffusion highlights some differences mostly depending on the skin nature (Table 3). Indeed, higher POX accumulation into skin surface, epidermis and dermis for the human skin decontamination with FE $5 \%$ suspensions is mainly due to an outlier in the dataset. For the SC compartment, there is a significant accumulation of the contaminant in the human abdominal skin in comparison with the pig ear skin. This can lead to a prolonged release even if the penetration kinetic of the POX shows a plateau from 8 hours in human skin, leading to same percentage of applied dose find in the receptor in the two skins for a given decontamination method.

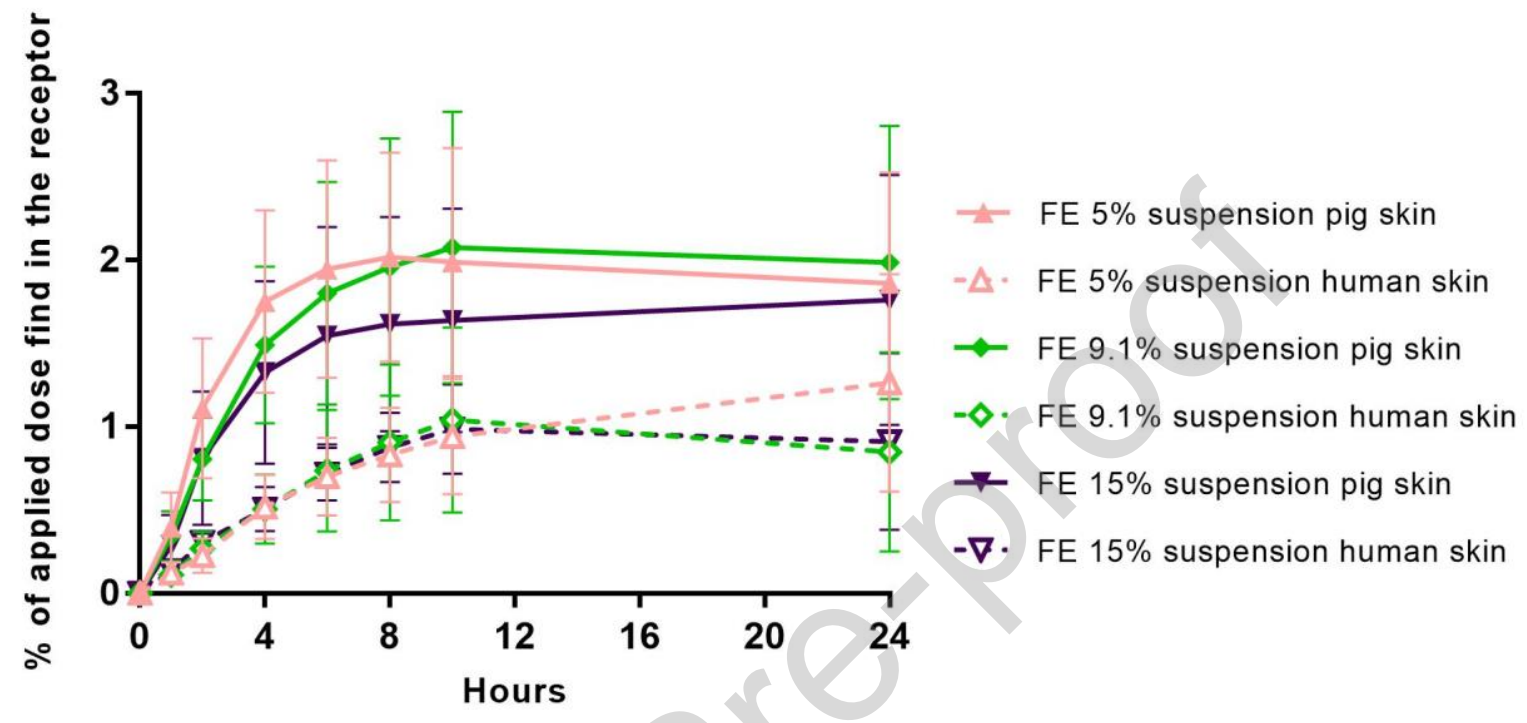

Figure 6: Ex vivo POX penetration assessment through pig ear skin and human abdominal skin with FE aqueous suspensions as decontaminant at 3 different concentrations (5\%, 9.1\% and 15\%): kinetic of diffusion through skin for 24 hours ( $n=6$ for each time). Results were statistically analyzed using two-way ANOVA followed by Tukey's multiple comparison tests. Values are presented as mean \pm SD.

Table 3: Percentage of applied dose of POX found at the skin surface, trapped into skin layers and passed through the skin after 24 hours of diffusion with FE aqueous suspensions as decontaminant at 3 different concentrations (5\%, 9.1\%, 15\%) into pig ear skin and human abdominal skin ( $n=6$ for each). Results were statistically analyzed using one-way ANOVA followed by Tukey's multiple comparison tests: comparison were made between all the values for given compartment and significance is by comparison with the letter (i.e., for skin surface, values are only significantly different to the one for human skin abdominal skin decontaminated with FE $5 \%$ suspension). Values are presented as mean. *: $p<0.05, * *: p<0.01, * * *: p<0.005$.

\begin{tabular}{|c|c|c|c|c|c|c|}
\hline $\begin{array}{l}\text { Decontamination } \\
\text { method }\end{array}$ & Skin model & Skin surface & $\begin{array}{l}\text { Stratum } \\
\text { corneum }\end{array}$ & Epidermis & Dermis & Receptor \\
\hline \multirow{2}{*}{ FE 5\% suspension } & Pig ear skin & $0.06 \%{ }^{*}(a)$ & $0.02 \%^{* *(b)}$ & $0 \%{ }^{*}(\mathrm{e})$ & $0.07 \%^{*}(f)$ & $1.86 \%$ \\
\hline & Human abdominal skin & $0.83 \%^{(a)}$ & $0.81 \%^{(\mathrm{b})}$ & $0.28 \%$ & $0.40 \%{ }^{(\mathrm{f})}$ & $1.26 \%$ \\
\hline \multirow{2}{*}{ FE $9.1 \%$ suspension } & Pig ear skin & $0.06 \%{ }^{*}(a)$ & $0 \%^{* * *}(c)$ & $0.01 \%{ }^{*}(e)$ & $0.02 \%^{*}(f)$ & $1.99 \%$ \\
\hline & Human abdominal skin & $0.48 \%$ & $0.87 \%^{(\mathrm{c})}$ & $0.29 \%^{(\mathrm{e})}$ & $0.29 \%$ & $0.85 \%$ \\
\hline \multirow{2}{*}{ FE $15 \%$ suspension } & Pig ear skin & $0.12 \%{ }^{*}(a)$ & $0.16 \%{ }^{*}(\mathrm{~d})$ & $0 \%{ }^{*}(\mathrm{e})$ & $0.04 \%^{*}(f)$ & $1.76 \%$ \\
\hline & Human abdominal skin & $0.53 \%$ & $0.78 \%^{(\mathrm{d})}$ & $0.18 \%$ & $0.13 \%$ & $0.91 \%$ \\
\hline
\end{tabular}

\subsection{Comparison of skin origins and of decontamination methods}

Decontamination methods were evaluated in comparison with POX skin contamination alone for both pig and human skins (Table 4). The quantity of contaminant absorbed by the skin, meaning find in the stratum corneum, the epidermis, the dermis and the receptor compartment, is significantly lower when decontamination methods are applied, no matter which type. Furthermore, for the same applied dose, the quantity of POX absorbed by human abdominal skin is significantly higher than the one for pig ear skin.

For both skin models, in vitro decontamination efficiency of FE powder is the lowest. Whereas there are not significant differences for the in vitro decontamination efficiencies depending on the decontamination method applied on pig ear skin, wet decontamination is significantly more effective than dry decontamination into 
human abdominal skin. The use of FE suspensions into pig ear skin leads to significant lower decontamination efficiencies values than the ones on human abdominal skin with the same aqueous decontaminants. Thus, it appears that pig ear skin is a good predictive model for the assessment of the decontamination efficiency because there is no risk of overestimation when extrapolated to human skin.

The functional prognosis improvement factor defined as the ability of each decontaminant to capture the contaminant on the skin surface (see materials and methods section 2.4.) is not impacted by the type of decontamination method used for a given skin origin. Although FE powder decontamination presents the lowest value in both skins, there are not significant differences with wet decontamination. However, the use of FE 5\% suspension induces an increase of the functional prognosis improvement factor significantly higher in the pig ear skin than in the human abdominal skin: these result can be explained by an exceptional value in the human skin dataset, increasing the global percentage of contaminant find on the skin surface. This factor can't be used to significantly classified decontamination methods according to their efficiency.

The more pronounced effect of the suspensions on pig ear skin is explained by histological differences with human skin, that will be discussed in the next session.

Table 4: Evaluation of skin decontamination methods following the quantity of POX absorbed by the skin (i.e. the percentage of applied dose find in the stratum corneum, the epidermis, the dermis and the receptor), the in vitro decontamination efficiency and the functional prognosis improvement depending on skin origin ( $n=6$ for each). Results were statistically analyzed using unpaired t-test for the comparison of each values of pig ear skin and human abdominal skin; and one-way ANOVA followed by Tuckey's multiple comparison test was used to compare values between them for a given skin origin. Values are presented as mean. *: $p<0.05 ;{ }^{* *}: p<0.01 ;{ }^{* * * *}: p<0.0001$.

\begin{tabular}{|c|c|c|c|c|c|c|}
\hline \multirow[b]{2}{*}{$\begin{array}{l}\text { Decontamination } \\
\text { method }\end{array}$} & \multicolumn{3}{|c|}{ Pig ear skin } & \multicolumn{3}{|c|}{ Human abdominal skin } \\
\hline & $\begin{array}{c}\text { Quantity of } \\
\text { POX } \\
\text { absorbed } \\
\text { by the skin }\end{array}$ & $\begin{array}{c}\text { In vitro } \\
\text { decontamination } \\
\text { efficiency }\end{array}$ & $\begin{array}{c}\text { Functional } \\
\text { prognosis } \\
\text { improvement } \\
\text { factor }\end{array}$ & $\begin{array}{l}\text { Quantity of } \\
\text { POX } \\
\text { absorbed by } \\
\text { the skin }\end{array}$ & $\begin{array}{c}\text { In vitro } \\
\text { decontamination } \\
\text { efficiency }\end{array}$ & $\begin{array}{l}\text { Functional } \\
\text { prognosis } \\
\text { improvement } \\
\text { factor }\end{array}$ \\
\hline $\begin{array}{l}\text { No } \\
\text { decontamination }\end{array}$ & $21.77 \%^{(a)}$ & & - & $76.15 \%^{(b)}$ & - & - \\
\hline $\begin{array}{l}\text { Fuller's earth } \\
\text { powder }\end{array}$ & $5.27 \%^{* * * *(a)}$ & $75.81 \%$ & 23.18 & $11.18 \%(\mathrm{c})$ & $85.32 \%^{(d)}$ & 14.53 \\
\hline Water & $2.81 \%^{* * * *}(a)$ & $87.11 \%$ & 48.71 & $2.62 \%^{* * * *}(\mathrm{~b})(\mathrm{c})$ & $96.55 \%{ }^{* * * *}(d)$ & 31.81 \\
\hline FE $5 \%$ suspension & $1.95 \%^{* * * *}(\mathrm{a})$ & $91.04 \%^{* *}$ & $53.19^{*}$ & $2.75 \%^{* * * *}(\mathrm{~b})(\mathrm{c})$ & $96.39 \%{ }^{* * * *}(d)$ & 23.51 \\
\hline $\begin{array}{ll}\mathrm{FE} & 9.1 \% \\
\text { suspension } & \end{array}$ & $2.01 \%^{* * * *}$ & $90.75 \%^{* *}$ & 53.10 & $2.30 \%^{* * * *(b)(c)}$ & $96.98 \%^{* * * *(d)}$ & 36.14 \\
\hline $\begin{array}{ll}\mathrm{FE} & 15 \% \\
\text { suspension } & \end{array}$ & $1.96 \%{ }^{* *}$ & $91.01 \%^{* *}$ & 71.5 & $2.00 \%^{* * * *}(\mathrm{~b})(\mathrm{c})$ & $97.38 \%{ }^{* * * *}(d)$ & 34.21 \\
\hline
\end{tabular}

\section{Discussion}

Toxicity of clays in general is not very well documented, and even more surprising when Fuller's earth (FE) is concerned, in particular its potential unsafe use regarding skin contact. First of all, when analyzing the toxicity of ultrafiltrable compounds released by water suspension of FE, our in vitro skin cells toxicity tests on filtered supernatant illustrated two information. Keratinocytes, which are cells from the epidermis, are not impacted in their viability by the application of neither PBS $1 \mathrm{X}$ or various concentrated supernatants of filtered FE suspensions. Although the measured toxicity of PBS $1 \mathrm{X}$ on NHDF can be attributed to their structural differences with HPKs (due to a stronger resilience and tolerance to external aggressions), it allows to determine that FE supernatants do not induce a higher cytotoxicity that PBS 1X. Han et al., 2011, previously demonstrated that clays suspensions at $1000 \mu \mathrm{g} / \mathrm{mL}$ are not toxic on human skin fibroblasts (CCD986sk) whereas Sandri et al., 2014, shaded this purpose by the observation of a tendency of decrease in cell viability of NHDF incubated with montmorillonite nanocomposites from 150 to $300 \mu \mathrm{g} / \mathrm{mL}$. However, in vitro toxicity assessment is highly dependent on the clay mineral and its structure in addition of the nature of the cell line (Maisanaba et al., 2015). Based on suspensions' effect of raw FE, the results on keratinocytes are in accordance with the ones of Janer et al., 2014, that recorded low toxicity of FE supernatants. To our knowledge, it is the first study that characterizes FE's intrinsic toxicity using Danio rerio model. Most of the time this type of 
experiment allows to determine adsorption properties of clays in order to diminish environmental water contamination (Gupta et al., 2016; Kansara et al., 2019). Here, the classical fish embryo toxicity test was coupled with a mobility test: no suspension has an effect of fish viability, while the more concentrated one has an impact on mobility. These results are in accordance with the ones of Abdel-Wahhab et al., 1999 and Dwyer et al., 1997, who gave ingested clays to rats and chickens in order to detoxify them after toxin ingestion. Neither models showed toxicity leading to the conclusion that clays are safe to use. Taken together, in vitro and in vivo toxicity tests suggest that FE suspensions are safe to use on undamaged and healthy skin in a concentration range from 5 to $9.1 \% \mathrm{w} / \mathrm{w}$.

Furthermore, pig ear skin was studied as a predictive model for ex vivo human skin decontamination studies of paraoxon as a model for VX organophosphorus compound. Indeed, although human excised skin is considered as the gold standard for in vitro skin penetration experiments (Barbero \& Frasch, 2009), its use is complicated due to ethical and supply difficulties. The presence of the papillary body and the large content in elastic tissue of its dermis in addition to the highly differentiated epidermis make pig skin a good substitute for human skin to assess ex vivo skin penetration. Just like for human skin, pig skin presents differences in terms of permeability as a function of the age, sex or anatomical region. In et al., 2019, compared histological and functional anatomical regions of porcine skin, including the ear, with human abdominal skin. Several significant differences have been identified, in particular for the SC, the dermo-epidermal interface and the dermis thickness that are larger in the human model. These variations in layer thickness leads to a significant difference in the epidermal-dermal thickness ratio; 1:19 for human abdominal skin versus 1:14 for pig ear skin. It means that even if both explants are dermatomed at $500 \mu \mathrm{m}$, the pig one has a larger dermal hydrophilic component. Despite these differences, skin from the pig ear is the more appropriate anatomical site in order to predict human skin penetration (Boudry et al., 2008; Gerstel et al., 2016; Schmook et al., 2001). Penetration abilities of various compounds are impacted by the skin nature which is mainly greater for animal skin than for human skin, leading to a possible overestimation of the human percutaneous absorption (Kraeling et al., 2018; Vallet et al., 2007).

The receptor medium could as well influence POX penetration behavior between human and pig skins. However, various studies have shown that receptor medium do not modify the differences of contaminant penetration between pig and human skin. For instance, a study by Boudry et al., 2008 showed higher parathion penetration in pig skin compared to human skin (7.5\% against $20.7 \%$ ), while using Eagle medium supplemented with BSA and Gentamycin as receptor medium. Similarly, Chilcott et al., 2001, showed that the absorption of Sulfur mustard through pig ear skin was 2.6 times higher than that of human skin using $50 \%$ aqueous ethanol in the receptor medium. Finally, other studies showed that using another receptor medium, such as ethanol and water (1:1) (Dalton et al., 2018; Thors et al.,2016) or HBSS solution (Bignon et al., 2017), does not impact the penetration of compounds through the skin. The use of different membranes origins at the interface of the diffusion device can lead to differences in the evaluation in skin decontaminants (Chilcott et al., 2001). Despite this, pig ear skin can be used as a cheap predictive model for human skin POX diffusion and its decontamination studies, whereas reconstructed skin could not be because of its weak barrier function (Schmook et al., 2001).

The improvement of decontamination efficiency for FE aqueous suspensions in comparison to FE powder or water alone can be explained by the molecular structure of the particles. Clays, more particularly smectites, are compounds of negatively charged organized units called lamellas, spaced by cations and water molecules, that are then organized as particles and further as aggregates (Salles et al., 2010). Generally speaking, the adsorption model for this type of material is based on pore diffusion through and inside aggregates before sorption by intern particles (van Beinum et al., 2005). This sorption mechanism was validated for pesticides: diffusion occurs through migration inside aggregates and their pores leading to the adsorption on the solid phase inside the aggregate before reaching a local equilibrium between the concentration in the pore solution and the locally absorbed concentration (Villaverde et al., 2009). Although the inter lamellar space is filled with cations, it remains the privileged area for chemical sorption with aggregates' surface (Shah et al., 2018). The nature of exchangeable cations and their degree of isomorphic substitution as well as the clay chemical composition are going to be key factors to understand clays' wettability properties with water (lannuccelli et al., 2016). Indeed, when clays are added in aqueous media, aggregates become oriented and ordered (Salles et al., 2010): lamellas are separated by water molecules layers and an increase in micropore size is observed as the result of the increase of basal space leading to a bigger BET surface area (the Brunauer, Emmet and Teller 
method permit to measure the surface areas) (Bertella \& Pergher, 2017). Hydration sequence is well described for smectites clay: firstly, an external hydration occurs on mesopore with single layers of water before filling of inter lamellar spaces and osmotic swelling.

With the use of FE suspensions, new hidden and non-accessible adsorption territories are released (van Beinum et al., 2005) which explains the decontamination efficiency improvement of water suspensions in comparison with dry FE. Nevertheless, this phenomenon is limited because intercalation of molecules into inter lamellar spaces is controlled by two parameters: attractive forces and cations exchange capacity (Moraes et al., 2017). This restriction explains the absence of a relationship between the concentration of suspensions and decontamination efficiency or functional prognosis improvement factor. All decontamination methods tested are significantly effective but depending on the decontaminant, different mechanisms are involved: for dry decontamination with FE as a powder, there is contaminant adsorption and fixation site saturation leading to free contaminant available to pass through skin layers. The excess contaminant will accumulate in the SC because of its lipophilic properties, and create a tank reservoir that allows a delayed release and a later contamination which is represented by a low Functional Prognosis, in accordance with the one found by Salerno et al., 2017 for FE powder applied on pig ear skin. To the opposite, wet decontamination with water alone allows only physical displacement and no adsorption with FE is involved. Thus, aqueous suspensions of FE used as innovative wet decontamination potentiates FE powder decontamination ability with the emergence of new adsorption sites as a result of inter lamellar swelling induced by water molecules. As it was already detailed for pesticide sorption by wet soils, contaminant will migrate by a diffusion phenomenon into aggregates' internal pores filled with water (Villaverde et al., 2009).

\section{Conclusion}

Fuller's earth (FE) is a smectite clay well known for its adsorbent properties used for household or skin decontamination. This compound is very heterogeneous in terms of nature and particle size as it is mostly composed of elementary clay aggregates and few amount of minerals such as heavy metals. Our results clearly indicate that aqueous suspension of $\mathrm{FE}$, regardless of its concentration, does not promote the release of toxic compounds from the clay. We have identified a minimal dose of $5 \%$ FE suspension in water as an optimal concentration for ex vivo dermal decontamination of paraoxon when loaded on porcine or human skin explants. Indeed, water suspension increases the decontaminant properties of FE, as noticed by the disappearance of a stratum corneum reservoir of paraoxon. All together these results are in favor of the use of water suspension of FE as a new tool to organophosphate decontamination.

\section{CRediT authorship contribution statement}

Alix Danoy: Conceptualization; Methodology; Formal analysis; Investigation; Writing - Original Draft; Writing Review \& Editing. Kardelen Durmaz: Investigation. Margaux Paoletti: Investigation. Laetitia Vachez: Methodology; Investigation. Annick Roul: Conceptualization. Jérôme Sohier: Review \& Editing, Bernard Verrier: Conceptualization; Resources; Writing - Review \& Editing; Supervision; Funding acquisition.

\section{Funding}

This research was founded by the Direction Générale de l'Armement DGA who paid Alix Danoy as PhD student, Laetitia Vachez is a recipient from ANR-16-CE20-0002-01 (FishRNAVax) and most part of this work has been funded by CNRS grant to Bernard Verrier.

\section{Acknowledgments}

We would like to thank Julien Rouleau for his advices during all the project, the PRECI (IGFL Lyon, SFR Biosciences) for animal housing and facilities, Damien Salmon for the supply of Vitropharma ${ }^{\circledR}$ device, Damien Ficheux and Maxime Dzikowski for the help for HPLC-UV method development. We would like to thank Fanny Charriaud for English language and style corrections. 


\section{References}

Abdel-Wahhab, M. A., Nada, S. A., \& Amra, H. A. (1999). Effect of aluminosilicates and bentonite on aflatoxininduced developmental toxicity in rat. Journal of Applied Toxicology: JAT, 19(3), 199-204. https://doi.org/10.1002/(sici)1099-1263(199905/06)19:3<199::aid-jat558>3.0.co;2-d

Barbero, A. M., \& Frasch, H. F. (2009). Pig and guinea pig skin as surrogates for human in vitro penetration studies : A quantitative review. Toxicology in Vitro: An International Journal Published in Association with BIBRA, 23(1), 1-13. https://doi.org/10.1016/j.tiv.2008.10.008

Bartelt-Hunt, S. L., Knappe, D. R. U., \& Barlaz, M. A. (2008). A Review of Chemical Warfare Agent Simulants for the Study of Environmental Behavior. Critical Reviews in Environmental Science and Technology, 38(2), 112-136. https://doi.org/10.1080/10643380701643650

Bertella, F., \& Pergher, S. B. C. (2017). Scale Up Pillaring : A Study of the Parameters That Influence the Process. Materials (Basel, Switzerland), 10(7). https://doi.org/10.3390/ma10070712

Bignon, C., Amigoni,S., Devers, T., \& Guittard, F. (2017). Barrier cream based on CeO2 nanoparticles grafted polymer as an active compound against the penetration of organophosphates. Chemico-Biological Interactions, Vol. 267, p17-24. 8p. https://doi.org/ 10.1016/j.cbi.2016.03.002

Bjarnason, S., Mikler, J., Hill, I., Tenn, C., Garrett, M., Caddy, N., \& Sawyer, T. W. (2008). Comparison of selected skin decontaminant products and regimens against VX in domestic swine. Human \& Experimental Toxicology, 27(3), 253-261. https://doi.org/10.1177/0960327108090269

Boudry, I., Blanck, O., Cruz, C., Blanck, M., Vallet, V., Bazire, A., Capt, A., Josse, D., \& Lallement, G. (2008). Percutaneous penetration and absorption of parathion using human and pig skin models in vitro and human skin grafted onto nude mouse skin model in vivo. Journal of Applied Toxicology: JAT, 28(5), 645-657. https://doi.org/10.1002/jat.1317

Chilcott, R. P., Jenner, J., Hotchkiss, S. A., \& Rice, P. (2001). In vitro skin absorption and decontamination of sulphur mustard : Comparison of human and pig-ear skin. Journal of Applied Toxicology: JAT, 21(4), 279-283. https://doi.org/10.1002/jat.755

Ciottone, G. R. (2018). Toxidrome Recognition in Chemical-Weapons Attacks. The New England Journal of Medicine, 378(17), 1611-1620. https://doi.org/10.1056/NEJMra1705224

Dalton, C., Hall, C., Lydon, H., Jenner, J., Chipman, J. K., Graham, J. S., \& Chilcott, R. P. (2018). The percutaneous absorption of soman in a damaged skin porcine model and the evaluation of WoundStatTM as a topical decontaminant. Cutaneous and Ocular Toxicology, 37(2), 172-179. https://doi.org/10.1080/15569527.2017.1365883

Denet, E., Espina-Benitez, M. B., Pitault, I., Pollet, T., Blaha, D., Bolzinger, M.-A., Rodriguez-Nava, V., \& Briançon, S. (2020). Metal oxide nanoparticles for the decontamination of toxic chemical and biological compounds. International Journal of Pharmaceutics, 583, 119373. https://doi.org/10.1016/j.ijpharm.2020.119373

Dwyer, M., Kubena, L., Harvey, R., Mayura, K., Sarr, A., Buckley, S., Bailey, R., \& Phillips, T. (1997). Effects of inorganic adsorbents and cyclopiazonic acid in broiler chickens. Poultry Science, 76(8), 1141-1149. https://doi.org/10.1093/ps/76.8.1141

Gerstel, D., Jacques-Jamin, C., Schepky, A., Cubberley, R., Eilstein, J., Grégoire, S., Hewitt, N., Klaric, M., Rothe, H., \& Duplan, H. (2016). Comparison of protocols for measuring cosmetic ingredient distribution in human and pig skin. Toxicology in Vitro: An International Journal Published in Association with BIBRA, 34, 153-160. https://doi.org/10.1016/j.tiv.2016.03.012

Godin, B., \& Touitou, E. (2007). Transdermal skin delivery : Predictions for humans from in vivo, ex vivo and animal models. Advanced Drug Delivery Reviews, 59(11), 1152-1161. https://doi.org/10.1016/j.addr.2007.07.004

Gupta, G. S., Dhawan, A., \& Shanker, R. (2016). Montmorillonite clay alters toxicity of silver nanoparticles in zebrafish (Danio rerio) eleutheroembryo. Chemosphere, 163, 242-251. https://doi.org/10.1016/j.chemosphere.2016.08.032 
Haines, D. D., \& Fox, S. C. (2014). Acute and Long-Term Impact of Chemical Weapons : Lessons from the IranIraq War. Forensic Science Review, 26(2), 97-114.

Han, H.-K., Lee, Y.-C., Lee, M.-Y., Patil, A. J., \& Shin, H.-J. (2011). Magnesium and calcium organophyllosilicates : Synthesis and in vitro cytotoxicity study. ACS Applied Materials \& Interfaces, 3(7), 2564-2572. https://doi.org/10.1021/am200406k

Hui, X., Domoradzki, J. Y., \& Maibach, H. C. (2012). In vitro study to determine decontamination of 3,5-dichloro2,4,6-trifluoropyridine (DCTFP) from human skin. Food and Chemical Toxicology: An International Journal Published for the British Industrial Biological Research Association, 50(7), 2496-2502. https://doi.org/10.1016/j.fct.2012.03.069

Iannuccelli, V., Maretti, E., Sacchetti, F., Romagnoli, M., Bellini, A., Truzzi, E., Miselli, P., \& Leo, E. (2016). CHARACTERIZATION OF NATURAL CLAYS FROM ITALIAN DEPOSITS WITH FOCUS ON ELEMENTAL COMPOSITION AND EXCHANGE ESTIMATED BY EDX ANALYSIS : POTENTIAL PHARMACEUTICAL AND COSMETIC USES. Clays and Clay Minerals, 64(6), 719-731. https://doi.org/10.1346/CCMN.2016.064038

In, M. K., Richardson, K. C., Loewa, A., Hedtrich, S., Kaessmeyer, S., \& Plendl, J. (2019). Histological and functional comparisons of four anatomical regions of porcine skin with human abdominal skin. Anatomia, Histologia, Embryologia, 48(3), 207-217. https://doi.org/10.1111/ahe.12425

Janer, G., Fernández-Rosas, E., Molino, E. M. del, González-Gálvez, D., Vilar, G., López-Iglesias, C., Ermini, V., \& Vázquez-Campos, S. (2014). In vitro toxicity of functionalised nanoclays is mainly driven by the presence of organic modifiers. Nanotoxicology, 8(3), 279-294. https://doi.org/10.3109/17435390.2013.776123

John, H., Balszuweit, F., Kehe, K., Worek, F., \& Thiermann, H. (2015). Chapter 56-Toxicokinetic Aspects of Nerve Agents and Vesicants. In R. C. Gupta (Éd.), Handbook of Toxicology of Chemical Warfare Agents (Second Edition) (p. 817-856). Academic Press. https://doi.org/10.1016/B978-0-12-800159-2.00056-7

Jung, E. C., \& Maibach, H. I. (2015). Animal models for percutaneous absorption. Journal of Applied Toxicology: $J A T$, 35(1), 1-10. https://doi.org/10.1002/jat.3004

Kansara, K., Paruthi, A., Misra, S. K., Karakoti, A. S., \& Kumar, A. (2019). Montmorillonite clay and humic acid modulate the behavior of copper oxide nanoparticles in aqueous environment and induces developmental defects in zebrafish embryo. Environmental Pollution (Barking, Essex: 1987), 255(Pt 2), 113313. https://doi.org/10.1016/j.envpol.2019.113313

Kherdekar, G., \& Adivarekar, R. V. (2017). Effect of different Wool Scouring Techniques on Physical Properties of Wool Fiber. International Journal of Modern Trends in Engineering \&amp; Research, 4(5), 163-167. https://doi.org/10.23883/ijrter.2017.3527.ndvmi

Kraeling, M. E. K., Topping, V. D., Keltner, Z. M., Belgrave, K. R., Bailey, K. D., Gao, X., \& Yourick, J. J. (2018). In vitro percutaneous penetration of silver nanoparticles in pig and human skin. Regulatory Toxicology and Pharmacology: RTP, 95, 314-322. https://doi.org/10.1016/j.yrtph.2018.04.006

Maisanaba, S., Pichardo, S., Puerto, M., Gutiérrez-Praena, D., Cameán, A. M., \& Jos, A. (2015). Toxicological evaluation of clay minerals and derived nanocomposites: A review. Environmental Research, 138, 233-254. https://doi.org/10.1016/j.envres.2014.12.024

Matar, H., Larner, J., Kansagra, S., Atkinson, K. L., Skamarauskas, J. T., Amlot, R., \& Chilcott, R. P. (2014). Design and characterisation of a novel in vitro skin diffusion cell system for assessing mass casualty decontamination systems. Toxicology in Vitro: An International Journal Published in Association with BIBRA, 28(4), 492-501. https://doi.org/10.1016/j.tiv.2014.01.001

Misik, J., Pavlikova, R., Cabal, J., \& Kuca, K. (2011). METHOD OF STATIC DIFFUSION CELLS FOR ASSESSMENT OF PESTICIDES SKIN PERMEATION. Military Medical Science Letters, 80, 46-51. https://doi.org/10.31482/mmsl.2011.007

Moore, C. A., Wilkinson, S. C., Blain, P. G., Dunn, M., Aust, G. A., \& Williams, F. M. (2014). Percutaneous absorption and distribution of organophosphates (chlorpyrifos and dichlorvos) following dermal exposure and decontamination scenarios using in vitro human skin model. Toxicology Letters, 229(1), 66-72. https://doi.org/10.1016/j.toxlet.2014.06.008 
Moraes, J. D. D., Bertolino, S. R. A., Cuffini, S. L., Ducart, D. F., Bretzke, P. E., \& Leonardi, G. R. (2017). Clay minerals : Properties and applications to dermocosmetic products and perspectives of natural raw materials for therapeutic purposes-A review. International Journal of Pharmaceutics, 534(1-2), 213-219. https://doi.org/10.1016/j.ijpharm.2017.10.031

Naughton, S. X., \& Terry, A. V. (2018). Neurotoxicity in acute and repeated organophosphate exposure. Toxicology, 408, 101-112. https://doi.org/10.1016/j.tox.2018.08.011

Netzlaff, F., Lehr, C.-M., Wertz, P. W., \& Schaefer, U. F. (2005). The human epidermis models EpiSkin ${ }^{\circledR}$, SkinEthic ${ }^{\circledR}$ and EpiDerm ${ }^{\circledR}$ : An evaluation of morphology and their suitability for testing phototoxicity, irritancy, corrosivity, and substance transport. European Journal of Pharmaceutics and Biopharmaceutics, 60(2), 167-178. https://doi.org/10.1016/j.ejpb.2005.03.004

Pitschmann, V. (2014). Overall view of chemical and biochemical weapons. Toxins, 6(6), 1761-1784. https://doi.org/10.3390/toxins6061761

Rehan, I., Khan, M. Z., Rehan, K., Sultana, S., Rehman, M. U., Muhammad, R., Ikram, M., \& Anwar, H. (2019). Quantitative analysis of Fuller's earth using laser-induced breakdown spectroscopy and inductively coupled plasma/optical emission spectroscopy. Applied Optics, 58(16), 4227-4233. https://doi.org/10.1364/AO.58.004227

Roul, A., Le, C.-A.-K., Gustin, M.-P., Clavaud, E., Verrier, B., Pirot, F., \& Falson, F. (2017). Comparison of four different fuller's earth formulations in skin decontamination. Journal of Applied Toxicology: JAT, 37(12), 1527-1536. https://doi.org/10.1002/jat.3506

Salerno, A., Devers, T., Bolzinger, M.-A., Pelletier, J., Josse, D., \& Briançon, S. (2017). In vitro skin decontamination of the organophosphorus pesticide Paraoxon with nanometric cerium oxide $\mathrm{CeO} 2$. Chemico-Biological Interactions, 267, 57-66. https://doi.org/10.1016/j.cbi.2016.04.035

Salles, F., Bildstein, O., Douillard, J. M., Jullien, M., Raynal, J., \& Van Damme, H. (2010). On the Cation Dependence of Interlamellar and Interparticular Water and Swelling in Smectite Clays. Langmuir, 26(7), 5028-5037. https://doi.org/10.1021/la1002868

Salmon, D., Gilbert, E., Gioia, B., Haftek, M., Pivot, C., Verrier, B., \& Pirot, F. (2015). New easy handling and sampling device for bioavailability screening of topical formulations. European Journal of Dermatology: EJD, 25 Supp/ 1, 23-29. https://doi.org/10.1684/ejd.2015.2551

Sandri, G., Bonferoni, M. C., Ferrari, F., Rossi, S., Aguzzi, C., Mori, M., Grisoli, P., Cerezo, P., Tenci, M., Viseras, C., \& Caramella, C. (2014). Montmorillonite-chitosan-silver sulfadiazine nanocomposites for topical treatment of chronic skin lesions : In vitro biocompatibility, antibacterial efficacy and gap closure cell motility properties. Carbohydrate Polymers, 102, 970-977. https://doi.org/10.1016/j.carbpol.2013.10.029

Schmook, F. P., Meingassner, J. G., \& Billich, A. (2001). Comparison of human skin or epidermis models with human and animal skin in in-vitro percutaneous absorption. International Journal of Pharmaceutics, 215(1-2), 51-56. https://doi.org/10.1016/s0378-5173(00)00665-7

Sellik, A., Pollet, T., Ouvry, L., Briançon, S., Fessi, H., Hartmann, D. J., \& Renaud, F. N. R. (2017). Degradation of paraoxon (VX chemical agent simulant) and bacteria by magnesium oxide depends on the crystalline structure of magnesium oxide. Chemico-Biological Interactions, 267, 67-73. https://doi.org/10.1016/j.cbi.2016.11.023

Shah, K. J., Pan, S.-Y., Shukla, A. D., Shah, D. O., \& Chiang, P.-C. (2018). Mechanism of organic pollutants sorption from aqueous solution by cationic tunable organoclays. Journal of Colloid and Interface Science, 529, 90-99. https://doi.org/10.1016/j.jcis.2018.05.094

Taylor, L., Brown, T., Benham, A., Lusty, P., \& Minchin, D. (2006). World mineral production 2000-04. British Geological Survey. http://www.bgs.ac.uk/mineralsuk/

Taysse, L., Daulon, S., Delamanche, S., Bellier, B., \& Breton, P. (2007). Skin decontamination of mustards and organophosphates : Comparative efficiency of RSDL and Fuller's earth in domestic swine. Human \& Experimental Toxicology, 26(2), 135-141. https://doi.org/10.1177/0960327107071866

Taysse, L., Dorandeu, F., Daulon, S., Foquin, A., Perrier, N., Lallement, G., \& Breton, P. (2011). Cutaneous challenge with chemical warfare agents in the SKH-1 hairless mouse (II) : Effects of some currently 
used skin decontaminants (RSDL and Fuller's earth) against liquid sulphur mustard and VX exposure. Human \& Experimental Toxicology, 30(6), 491-498. https://doi.org/10.1177/0960327110373616

Thors, L., Koch, B., Koch, M., Hägglund, L., \& Bucht, A. (2016). In vitro human skin penetration model for organophosphorus compounds with different physicochemical properties. Toxicology in Vitro: An International Journal Published in Association with BIBRA, 32, 198-204. https://doi.org/10.1016/j.tiv.2016.01.003

Vallet, V., Cruz, C., Josse, D., Bazire, A., Lallement, G., \& Boudry, I. (2007). In vitro percutaneous penetration of organophosphorus compounds using full-thickness and split-thickness pig and human skin. Toxicology in Vitro: An International Journal Published in Association with BIBRA, 21(6), 1182-1190. https://doi.org/10.1016/j.tiv.2007.03.007

van Beinum, W., Beulke, S., \& Brown, C. D. (2005). Pesticide sorption and diffusion in natural clay loam aggregates. Journal of Agricultural and Food Chemistry, 53(23), 9146-9154. https://doi.org/10.1021/jf050928g

Villaverde, J., van Beinum, W., Beulke, S., \& Brown, C. D. (2009). The kinetics of sorption by retarded diffusion into soil aggregate pores. Environmental Science \& Technology, 43(21), 8227-8232. https://doi.org/10.1021/es9015052

Graphical abstract

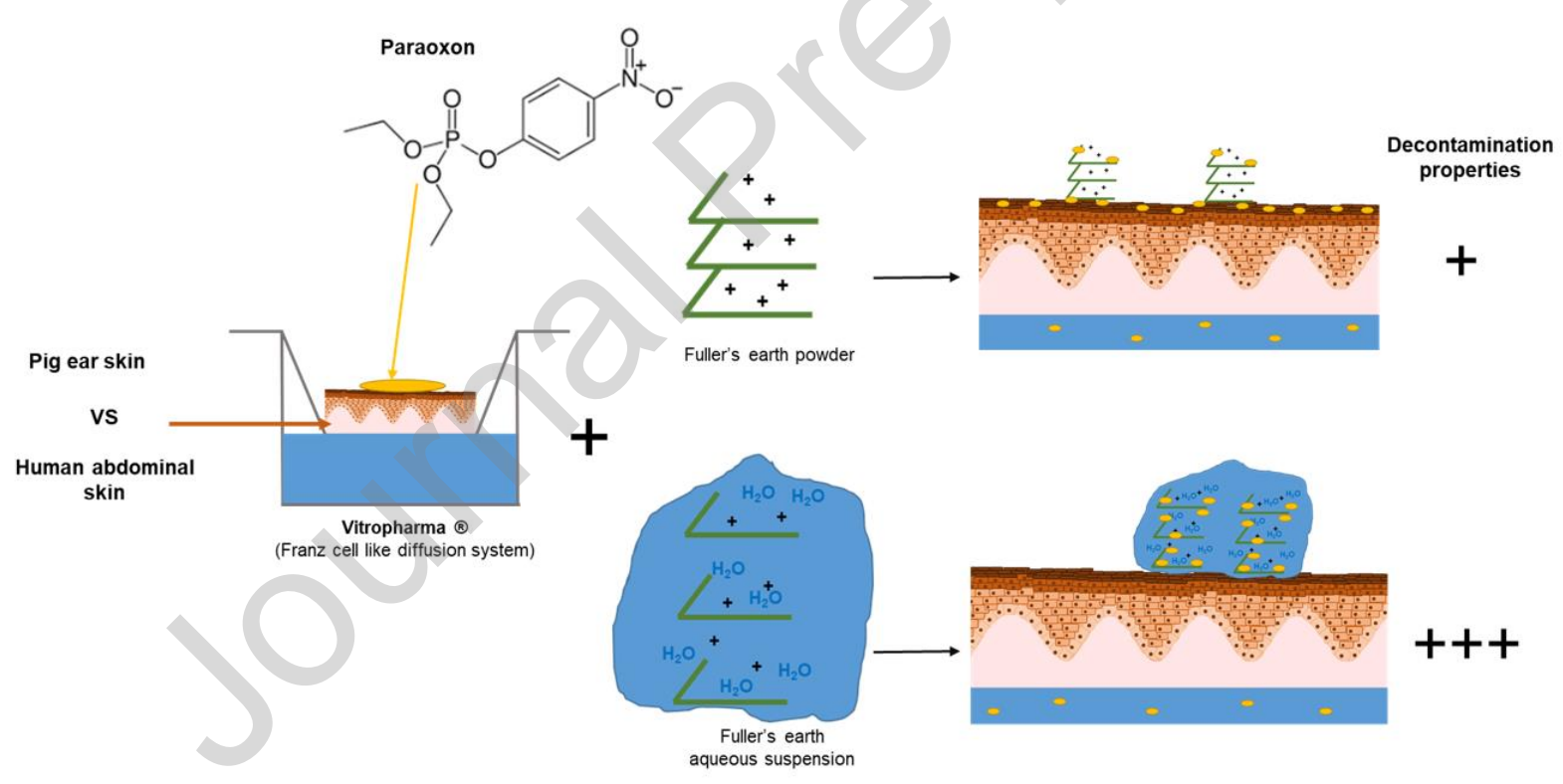

\section{CRediT authorship contribution statement}

Alix Danoy: Conceptualization; Methodology; Formal analysis; Investigation; Writing - Original Draft; Writing Review \& Editing. Kardelen Durmaz: Investigation. Margaux Paoletti: Investigation. Laetitia Vachez: Methodology; Investigation. Annick Roul: Conceptualization. Jérôme Sohier: Review \& Editing. Bernard Verrier: Conceptualization; Resources; Writing - Review \& Editing; Supervision; Funding acquisition. 


\section{Declaration of interests}

$\bigotimes$ The authors declare that they have no known competing financial interests or personal relationships that could have appeared to influence the work reported in this paper.

$\square$ The authors declare the following financial interests/personal relationships which may be considered as potential competing interests:

\section{Highlights:}

- Fuller's earth is non-toxic in vitro and in vivo

- Increase of the decontamination efficiency not related to the clay concentration

- Water drags the contaminant deeper into the pores of the Fuller's earth

- Pig ear skin as cheap predictive model for human skin contamination with paraoxon 